\title{
KESAN PENAMBAHAN HABUK KAYU CENGAL TERHADAP SIFAT KEKERASAN LDPE (Low Density Polyethelene)
}

\author{
MOHD SOBRI BIN HUSSIN* \\ SHAMSUDDIN BIN ABDULLAH** \\ AHMAD FARUDZI BIN AZIB***
}

\begin{abstract}
Abstrak
Kajian ini melibatkan Polietelena Berketumpatan Rendah (LDPE) diadun dengan bahan tambah iaitu habuk kayu Cengal (HK). Habuk kayu dapat dimajukan, ini kerana sisa kayu dapat mengurangkan kos penggunaan bahan asli dalam pengeluaran. Lantaran itu, kajian dilakukan berhubung dengan kekekerasan sesuatu bahan campuran yang dihasilkan. Oleh itu, satu kajian dilakukan bagi menentukan kesan penambahan habuk kayu terhadap kekerasan bahan LDPE yang akan dihasilkan. Kajian dilakukan dengan melihat kesan ke atas penambahan habuk kayu dengan sifat LDPE tulen. Pemerhatian dilakukan terhadap sifat mekanikal LDPE yang dikurangkan kuantiti jisimnya dengan nisbah penambahan habuk kayu sebanyak 3, 6, 9, 12 dan 15 peratus. Habuk kayu diayak menerusi pengayak yang bersaiz 200 $\mu \mathrm{m}$ dan ditimbang mengikut campuran penambahan. Sampel dihasilkan menggunakan mesin suntikan panas bagi tujuan ujian kekerasan. Keputusan ujian dianalisa bertujuan untuk membuat perbandingan dengan $100 \%$ LDPE dengan peratusan HK yang ditetapkan. Ujian kekerasan secara keseluruhannya meningkat. Peningkatan paling tinggi adalah pada sampel $12 \%$ HK iaitu sebanyak $8.2 \%$. Dalam kajian ini kekerasan bahan meningkat dengan penambahan HK. Kajian lanjut tentang kekuatan bahan boleh diteruskan melalui penambahan saiz partikel pengisi yang lebih halus.
\end{abstract}

Kata kunci: Habuk kayu chengal, LDPE, Ujian kekerasan, Peratusan yang ditetapkan, Kekerasan meningkat

* Pensyarah/ ljazah sarjana muda di Jab. Kej. Mekanikal/ Politeknik Kota Bharu.

** Pensyarah/ ljazah sarjana muda di Jab. Kej. Mekanikal/ Politeknik Kota Bharu.

*** Pensyarah/ ljazah sarjana muda di Jab. Kej. Mekanikal/ Politeknik Kota Bharu. 


\begin{abstract}
The study involved Low Density Polyethylene (LDPE) blended with additive that is sawdust Cengal (HK). Sawdust can be developed, because wood waste can reduce the use of natural materials in production. Thus, a study was undertaken in relation to the hardness of the produced mixture. Therefore, a study was conducted to determine the effect of wood dust on he hardness of the produced mixture LDPE material to be produced. The study was undertaken by looking at the effect of adding the quantity of sawdust to the nature of pure LDPE. Observations were made on the mechanical properties of LDPE when the quantity of mass is reduced by increasing the sawdust ratio from 3 to 6, 9, 12 and 15 percent. Sawdust was sifted through a sieve with the size of $200 \mu \mathrm{m}$ and weighed by the addition of a mixture. Samples for hardness test were produced by using injection hot machine. The test results are analyzed in order to make a comparison with $100 \%$ LDPE with HK prescribed percentage. (It is found that overall, the hardness of the produced mixture has increase. The highest increase (8.2\%) was shown by the $12 \% \mathrm{HK}$ sample). In this study, the hardness increased with the addition of HK. Further study of the strength of the material can be pursued through the addition of finer particle size filler.
\end{abstract}

Keywords: Sawdust chengal, LDPE, Hardness test, A set percentage, increased violence

* Pensyarah/ ljazah sarjana muda di Jab. Kej. Mekanikal/ Politeknik Kota Bharu.

** Pensyarah/ ljazah sarjana muda di Jab. Kej. Mekanikal/ Politeknik Kota Bharu.

*** Pensyarah/ ljazah sarjana muda di Jab. Kej. Mekanikal/ Politeknik Kota Bharu. 


\subsection{Pengenalan}

Kajian ini tertumpu kepada kesan penambahan habuk kayu cengal terhadap kekerasan LDPE. LDPE merupakan Polietilena Berketumpatan Rendah, manakala habuk kayu Cengal pula merupakan bahan tambah yang akan digunakan di dalam projek ini. Walaubagaimanapun peratusan yang akan menentukan mutu produk atau gaulan komersial adalah tidak melebihi tiga puluh peratus habuk kayu dan tidak kurang daripada tujuh puluh peratus LDPE.

Polietilena (PE) merupakan salah satu polimer yang biasa kita lihat dalam kehidupan seharian. la adalah polimer yang digunakan untuk membuat beg plastik, botol syampu, alat permainan kanakkanak, dan juga baju kalis peluru. Sebagai polimer yang serba-guna, ia mempunyai struktur yang sangat mudah berbanding dengan struktur polimer komersil yang lain. Molekul-molekul polietilena (PE) terdiri daripada satu rantai atom karbon yang panjang dengan dua atom hidrogen terikat pada setiap atom karbon. Rajah 1 menunjukkan formula unit Polietilena PE.

\section{$+\mathrm{CH}_{2}-\mathrm{CH}_{2}+_{\mathrm{n}}$}

Rajah 1: Unit Polietilena PE

\subsection{Rasional Kajian}

Berikut adalah masalah-masalah yang timbul apabila polimer LDPE digunakan secara bersendirian tanpa campuran bahan pengisi:

i) Polimer LDPE sangat mudah bercalar.

ii) Polimer LDPE cenderung untuk rosak apabila diwarnakan.

iii) Polimer LDPE mempunyai kekuatan dan kekakuan yang sangat rendah dan mudah dipengaruhi oleh retak tegasan. 
Oleh itu, dengan mencampurkan polimer LDPE dengan habuk kayu cengal diharapkan dapat mengatasi masalah-masalah yang dinyatakan di atas. Habuk kayu merupakan bahan buangan, mungkin dengan penambahan ini mampu mengurangkan kos bahan tersebut. Kajian ini melibatkan penghasilan satu campuran bahan yang sesuai antara polimer polietilena berketumpatan rendah (LDPE) dan habuk kayu melalui kaedah penekanan panas (Roll Mill Mixer) dan pengacuanan suntikan panas (Injection Moulding). Bahan ini seterusnya diuji dari aspek-aspek mekanikal iaitu melalui ujian kekerasan.

\subsection{Objektif Kajian}

Membandingkan sifat kekerasan polimer tulen LDPE 100\% dengan nisbah campuran LDPEhabuk kayu cengal.

\subsection{Skop Kajian}

Skop kajian projek ini adalah seperti berikut:

i) Menjalankan kajian literatur tentang polimer LDPE dan habuk kayu cengal.

ii) Menghasilkan campuran polimer LDPE dengan habuk kayu cengal dengan peratusan yang ditetapkan.

iii) Menyediakan sampel ujikaji daripada campuran polimer LDPE dan habuk kayu cengal.

iv) Menjalankan ujian kekerasan ke atas sampel yang telah dibuat.

v) Menganalisis data-data dan keputusan serta membandingkan sifat-sifat yang dihasilkan dengan polimer LDPE tulen. 


\subsection{Kajian Literatur}

Dalam kajian yang akan dibuat, beberapa jurnal yang berkaitan dengan polimer LDPE yang dicampur dengan pengisi tertentu telah dirujuk untuk menjadi garis panduan serta untuk melihat parameterparameter penting bagi kajian ini.

\subsection{Komposit LDPE Diperkuatkan Dengan Gentian Pendek Daun Nenas}

Nyamol George, S.S Bhagawan, N.Prabhakaran dan Sabu Thomas (1995), telah mengkaji tentang kesan polimer LDPE diperkuatkan dengan gentian pendek daun nenas. Mereka telah menganalisis tentang kesan keadaan pemprosesan, pembebanan gentian, penyesuaian gentian dan panjang gentian kepada sifat-sifat fizikal-mekanikal komposit tersebut. Peratusan gentian daun nenas yang digunakan dalam percampuran ini adalah ditambah beransur-ansur dari $0 \%$ sehingga $30 \%$ dengan pertambahan sebanyak 10\% setiap kali campuran. Daripada kajian ini, didapati, keadaan-keadan berikut adalah pada keadaan optimum :

i) Masa percampuran : 6 minit

ii) Laju pemutar : $60 \mathrm{rpm}$

iii) Suhu percampuran : $130^{\circ} \mathrm{C}$

Melalui kaedah ini, setelah mempertimbangkan keseluruhan sifat-sifat mekanikal dan ciriciri pemprosesan, didapati panjang gentian berukuran $6 \mathrm{~mm}$ merupakan panjang yang paling optimum untuk diperkuatkan di dalam LDPE. Selain itu, sifat-sifat mekanikal didapati bartambah dan pemanjangannya berkurangan dengan penambahan pembebanan gentian. (Nyamol George, S. S. Bhagawan, N. Prabhakaran and Sabu Thomas ,1995). 


\subsection{Ujian Kekerasan}

Ujian kekerasan merupakan ujian yang paling lazim digunakan untuk mengetahui atau menganggar sifat mekanikal sesuatu bahan. Kekerasan boleh ditakrifkan sebagai bahan yang merintangi pelekukan kekal semasa bahan dikenakan beban statik atau dinamik. Kekerasan boleh juga ditakrifkan sebagai rintangan terhadap calar atau haus. Terdapat pelbagai teknik yang digunakan untuk mengukur kekerasan sesuatu bahan, antaranya ujian kekerasan Brinell, Rockwell, Vickers dan Knoop. Rajah 2 menunjukkan kaedah-kaedah ujian kekerasan.

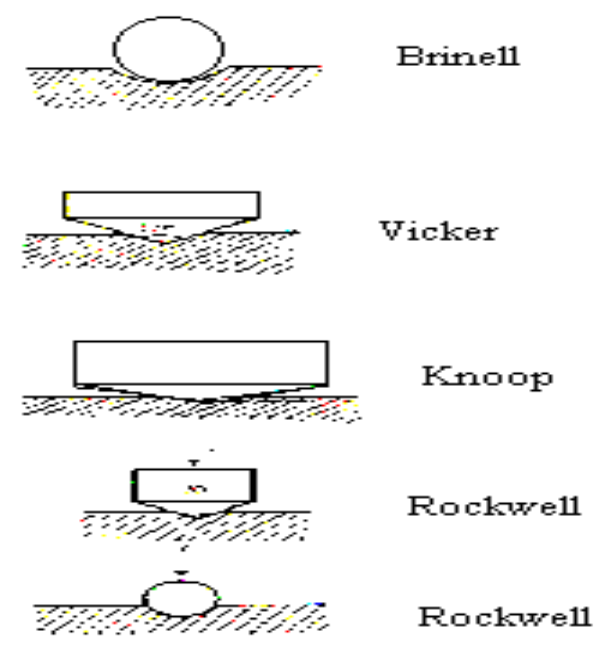

Rajah 2: Menunjukkan kaedah-kaedah ujian kekerasan

Pengiraan yang akan dilakukan melalui data ujikaji yang dijalankan:-

Nombor kekerasan Brinell, $\mathrm{HB}_{\mathrm{B}}=$ Beban yang dikenakan, $\mathrm{P}(\mathrm{kg})$

Luas permukaan lekukan, $\mathrm{A}\left(\mathrm{mm}^{2}\right)$ 
Setelah pengukuran kekerasan Brinell, Нв dibuat, parameter yang diukur ialah garis pusat lekukan, $\mathrm{d}$ berada diantara $0.25 \mathrm{D}$ dengan $0.5 \mathrm{D}$ dimana $\mathrm{D}$ sebagai garispusat bebola tersebut. Luas permukaan lekukan, A ialah:-

$$
\begin{aligned}
& \text { Luas, } A \quad=л D / 2\left(D-\sqrt{ }\left(D^{2}-d^{2}\right)\right) \\
& \text { Dan juga, } H_{B}=\frac{2 F \ldots \ldots . . .}{ת D\left(D-\sqrt{ }\left(D^{2}-d^{2}\right)\right)}
\end{aligned}
$$

Dimana F ialah beban yang digunakan dalam unit Newton (beban, P X Graviti, G). Ujian ini tidak sesuai untuk pengujian bahan yang keras. Ini kerana jika kekerasan bahan yang hendak diuji

\begin{tabular}{|c|c|c|c|c|c|c|c|c|c|}
\hline$H_{\mathrm{D}}$ & $H_{\mathrm{B}}$ & $H_{\mathrm{RB}}$ & $H_{\mathrm{RC}}$ & Shore & $H_{\mathrm{D}}$ & $H_{\mathrm{B}}$ & $H_{\mathrm{RB}}$ & $H_{\mathrm{RC}}$ & Shore \\
\hline 20 & 19 & & & & 520 & 482 & & 51.1 & 66.5 \\
\hline 40 & 38 & & & & 540 & 497 & & 52.4 & 68.0 \\
\hline 60 & 57 & & & & 560 & 512 & & 53.7 & 69.5 \\
\hline 80 & 76 & 31.9 & & & 580 & 527 & & 54.8 & 71.5 \\
\hline 100 & 95 & 52.5 & & & 600 & 542 & & 55.7 & 73.0 \\
\hline 120 & 114 & 66.3 & & & 620 & 555 & & 56.7 & 74.5 \\
\hline 140 & 133 & 76.1 & & & 640 & 568 & & 58.6 & 76.0 \\
\hline 160 & 152 & 83.4 & & & 660 & 580 & & 58.5 & 77.5 \\
\hline 180 & 171 & 89.2 & & & 680 & 592 & & 59.3 & 79.0 \\
\hline 200 & 190 & 93.8 & 14.0 & 31.5 & 700 & 602 & & 60.1 & 80.5 \\
\hline 220 & 209 & 97.5 & 18.0 & 34.5 & 720 & & & 60.9 & 82.0 \\
\hline 240 & 228 & & 21.8 & 38.0 & 740 & & & 61.7 & 83.5 \\
\hline 260 & 247 & & 25.1 & 40.5 & 760 & & & 62.5 & 85.0 \\
\hline 280 & 266 & & 28.2 & 46.0 & 780 & & & 63.3 & 86.5 \\
\hline 300 & 285 & & 30.0 & 45.5 & 800 & & & 64.0 & 88.0 \\
\hline 320 & 304 & & 33.4 & 48.0 & 820 & & & 64.8 & 89.0 \\
\hline 340 & 323 & & 35.7 & 50.0 & 840 & & & 65.5 & 90.5 \\
\hline 360 & 342 & & 37.8 & 52.0 & 860 & & & 66.3 & 92.0 \\
\hline 380 & 361 & & 39.8 & 54.0 & 880 & & & 67.0 & 93.5 \\
\hline 400 & 380 & & 41.7 & 55.5 & 900 & & & 67.7 & 94.5 \\
\hline 420 & 399 & & 43.5 & 57.5 & 920 & & & & 96.0 \\
\hline 440 & 418 & & 45.1 & 59.5 & 940 & & & & 97.5 \\
\hline 460 & 437 & & 46.7 & 61.0 & 960 & & & & 98.5 \\
\hline 480 & 452 & & 48.2 & 63.0 & 980 & & & & 100.0 \\
\hline 500 & 467 & & 49.7 & 64.5 & 1000 & & & & 101.0 \\
\hline
\end{tabular}
melebihi kekerasan bola pelekuk, pelekuk akan mengalami perubahan bentuk.

Jadual 1 : Pertukaran nombor kekerasan

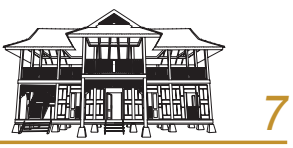


Meter keras Jermang (Shore Durometer) digunakan bagi pengukuran kekerasan terhadap bahan polimer. Terdapat dua jenis meter keras iaitu jenis A dan D. Kedua-duanya mempunyai mata penusuk spring berbeban yang digunakan untuk menolak permukaan sampel. Kerintangan bahan untuk menolak spring tersebut akan memberikan nilai kekerasan. Jenis meter keras $A$ menggunakan bebanan spring dari 56 hingga 822 gram manakala jenis meter keras $D$ dari 0 hingga $10 \mathrm{lb}$. Kedua-dua jenis meter ini akan memberikan nilai kekerasan 0 hingga 100 pada skala Shore dengan mengukur keanjalan permukaan sebagai penunjuk kekerasan. Meter keras jenis A digunakan untuk ujian kekerasan pada sampel. Ketebalan sampel yang diuji mesti tidak kurang daripada $6 \mathrm{~mm}$. Suhu sampel mestilah berada dalam suhu bilik sebelum ujian dilakukan kerana suhu memainkan peranan penting dalam memberi nilai kekerasan yang sebenar.

Tekanan yang dikenakan ketika ujian dijalankan mestilah seragam. Bacaan kekerasan mesti diambil pada permukaan sampel yang rata dan bacaan pada meter ini diambil selepas satu saat penusuk pegas berbeban ini menekan permukaan sampel. Anggaran pertukaran nilai kekerasan Shore durometer dengan nombor kekerasan yang lain boleh dirujuk pada Jadual 1.

Secara amnya apabila nilai kekerasan sesuatu bahan meningkat, sifat lain seperti kekuatan tegangan, mampatan dan ricihan juga akan meningkat. Ujian kekerasan merupakan proses yang paling cepat, mudah yang digunakan untuk menganggar bagi menilai kekuatan tegangan sesuatu bahan. Ujian ini juga digunakan untuk menilai kemuluran dan kekerasan sesuatu bahan. Kebanyakkan bahan yang mempunyai nilai kemuluran yang tinggi selalunya lembut dan apabila kemuluran berkurang, kekerasan akan meningkat. Bahan yang sangat keras mempunyai kecenderungan untuk menjadi sangat rapuh, tetapi ini adalah dinilai secara kasar, bukannya persamaan empirik yang membolehkan nombor kekerasan ditukar kepada nilai kekuatan tegangan, hentaman dan sebagainya. 


\subsection{Carta Alir Metodologi}

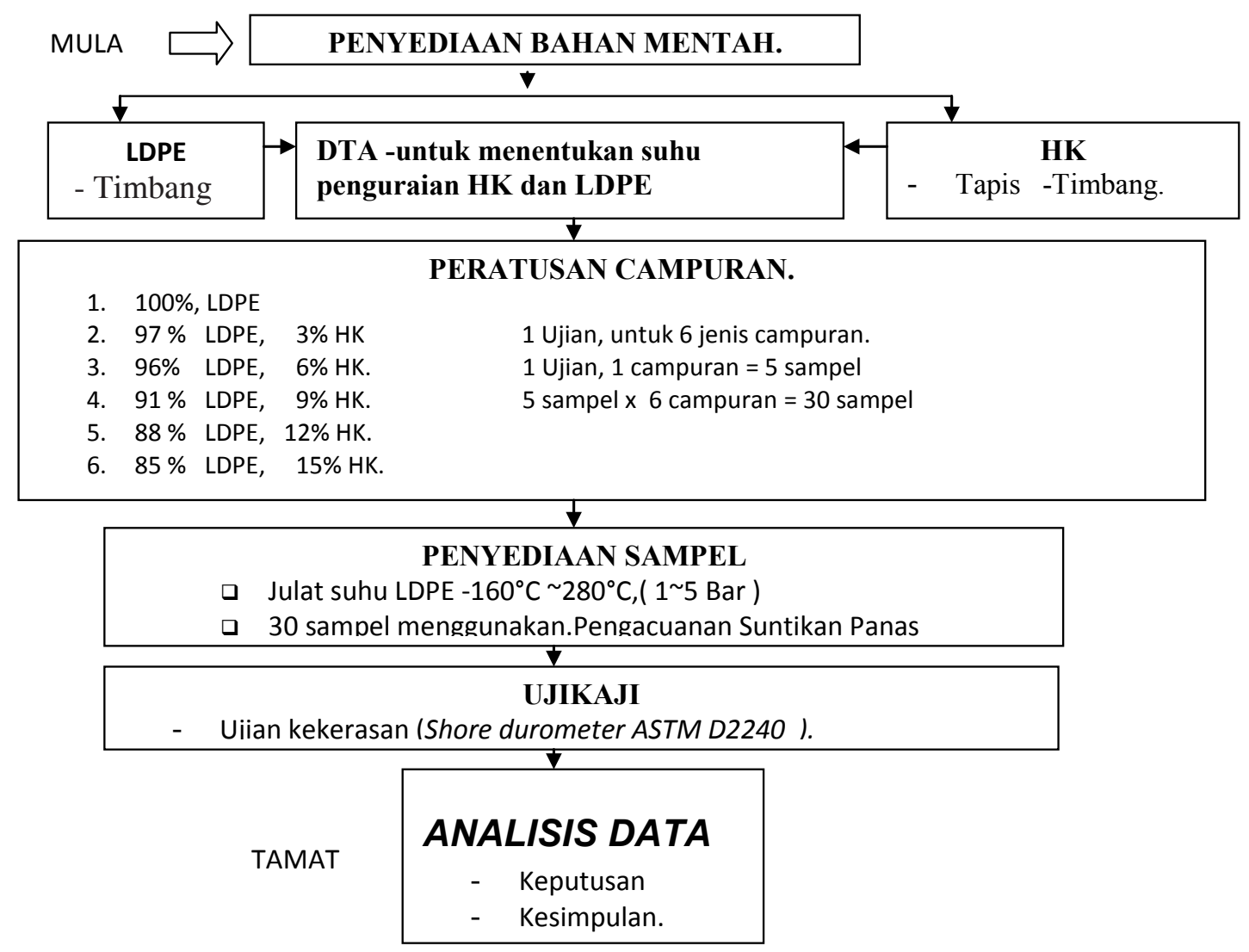

Rajah 3: Carta Analisis Sampel 


\subsection{Keputusan, Pemerhatian Dan Analisa}

\subsection{Pengenalan}

Data-data ini diolah dan di analisis untuk mengetahui sifat-sifat mekanikal LDPE $100 \%$ dan peratusan nisbah campuran lain yang merangkumi:

\section{Analisis terma DTA.}

2. Ujian kekerasan (hardness test)

Data-data yang diperoleh diolah dalam bentuk graf agar sifat-sifat sesuatu bahan dapat dilihat dengan jelas dan dapat memberikan ulasan yang berdasarkan kepada teori yang berkaitan dengannya. Rajah 4 menunjukkan graf berkomputer ujian DTA bagi LDPE dan Rajah 5 menunjukkan graf berkomputer ujian DTA bagi HK.

\section{Analisis Terma}

\section{Keputusan Analisis DTA Untuk LDPE}

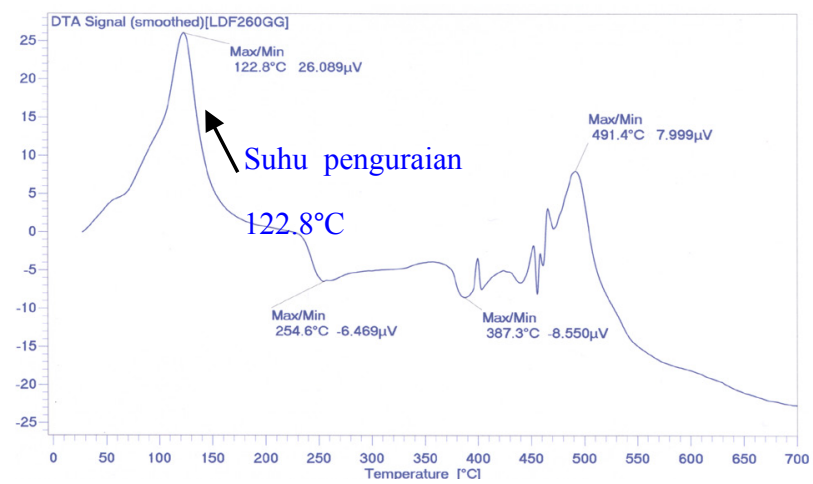

Rajah 4: Menunjukkan graf berkomputer ujian DTA bagi LDPE 


\section{Keputusan Analisis DTA Untuk HK}

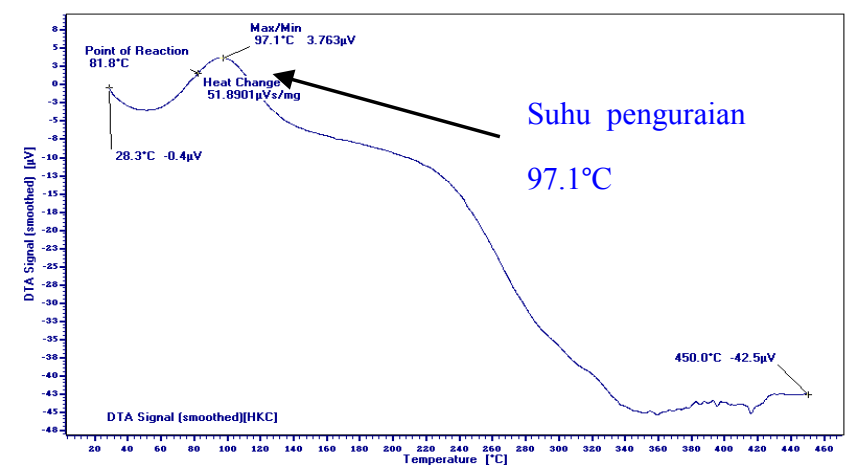

Rajah 4: Menunjukkan graf berkomputer ujian DTA bagi HK

\subsection{Pemerhatian}

Ujian DTA dilakukan untuk mengetahui suhu penguraian LDPE dan HK bagi menentukan parameter suhu semasa proses penghasilan sampel. Suhu penguraian sampel penting bagi mengetahui pada suhu berapakah sesuatu bahan itu mengurai. Daripada ujikaji DTA yang dilakukan ke atas LDPE dan HK, suhu penguraian bagi LDPE adalah $122.8^{\circ} \mathrm{C}$ manakala suhu penguraian bagi HK pula $97.1^{\circ} \mathrm{C}$. Suhu ini digunakan bagi parameter semasa melakukan proses pembuatan sampel. 


\subsection{Ujian Kekerasan}

Jadual 2: Menunjukkan keputusan ujian kekerasan

\begin{tabular}{|l|l|l|l|l|l|l|}
\hline \multirow{2}{*}{$\begin{array}{l}\text { Nisbah } \\
\text { Campuran }\end{array}$} & \multicolumn{7}{l}{ BACAAN (Shore Durometer) } \\
\cline { 2 - 7 } & S-1 & S-2 & S-3 & S-4 & S-5 & Purata \\
\hline 100\% LDPE & 40.6 & 40.3 & 40.6 & 39 & 40.6 & 40.2 \\
\hline $97 \%$ LDPE 3\% HK & 41.6 & 41.6 & 42.3 & 41.6 & 41.3 & 41.6 \\
\hline $97 \%$ LDPE 6\% HK & 42.6 & 44.0 & 43.3 & 43.3 & 42.3 & 43.1 \\
\hline $91 \%$ LDPE 9\% HK & 44.0 & 42.6 & 43.3 & 45.3 & 43.6 & 43.8 \\
\hline $88 \%$ LDPE 12\% HK & 45.3 & 43.0 & 44.0 & 44.0 & 43.0 & 43.8 \\
\hline $85 \%$ LDPE 15\% HK & 40.6 & 40.6 & 41.3 & 42.6 & 40.6 & 41.2 \\
\hline
\end{tabular}

\subsubsection{Data Ujikaji}

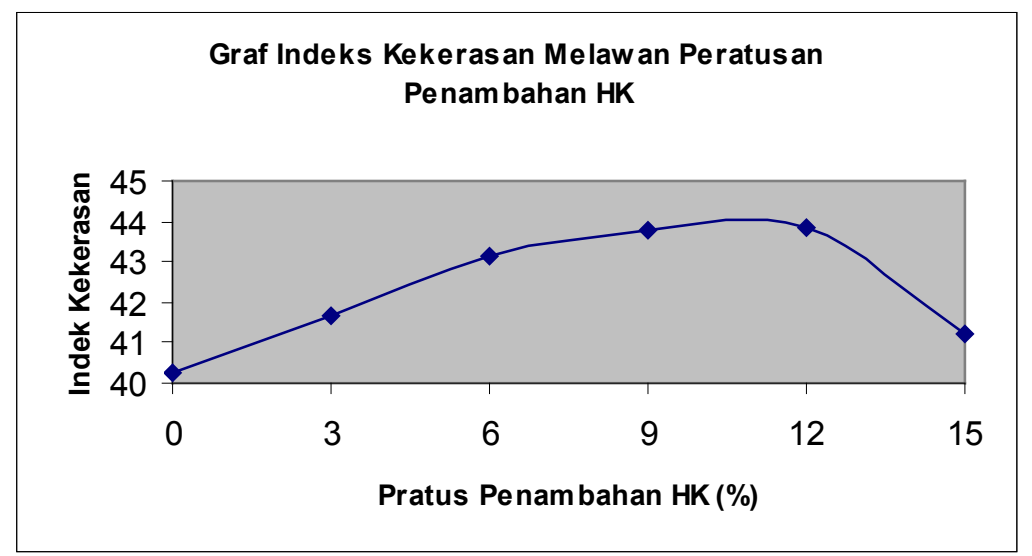

Rajah 6: Graf menunjukkan indek kekerasan melawan nisbah campuran HK yang berbeza

\subsubsection{Pemerhatian}

Semua data mengenai ujian kekerasan diambil dan dicatat pada Jadual 2. Setiap sampel bacaan diambil sebanyak 5 kali dan nilai purata dikira bagi memastikan ketepatannya. Data-data ini digunakan untuk memplot graf jenis indek kekerasan 
melawan peratus penambahan HK. Berdasarkan Rajah 5, menunjukkan kepada data dan graf yang diplotkan, peningkatan kekerasan jelas dapat dilihat. Semakin banyak peratusan habuk kayu maka semakin tinggi nilai kekerasanya dan akan menurun pada sampel $15 \%$ habuk kayu.

Sampel 88\% LDPE 12\% HK merupakan campuran yang mempunyai nilai indeks kekerasan yang paling tinggi jika dibandingkan dengan nilai purata bacaan yang lain, ini menunjukkan bahawa sampel ini semakin kurang keliatannya. Peningkatan berlaku secara sekata bermula dari Sampel 100\% LDPE yang mempunyai nilai indeks kekerasan adalah 40.2, sampel 97\% LDPE 3\% HK nilai indeks kekerasannya adalah 41.6, sampel 96\% LDPE $6 \%$ HK. Indeks kekerasannya adalah 43.1, sampel 91\% LDPE 9\% HK indeks kekerasan adalah 43.8, manakala sampel $88 \%$ LDPE 12\% HK mempunyai nilai kekerasan 43.9 dan sebaliknya berlaku pada sampel $85 \%$ LDPE $15 \%$ HK iaitu menurun sedikit daripada sampel $88 \%$ LDPE $12 \%$ HK iaitu indeks kekerasannya 41.2. Peratusan peningkatan ini, jika dibandingkan dengan sampel 100\% LDPE adalah seperti di dalam Jadual 3. Menurut Rao dan Lee (1994), dengan penambahan bahan pengisi yang berbentuk ion atau partikel dalam polimer akan menyebabkan nilai kekerasan komposit polimer dengan pengisi berkecenderungan untuk bertambah.

Jadual 3: Menunjukkan peratusan peningkatan indek kekerasan yang dibandingkan dengan Sampel $100 \%$ LDPE

\begin{tabular}{|l|l|l|}
\hline Sampel & Purata & Peratus peningkatan nilai indeks kekerasan \\
\hline 100\% LDPE & 40.6 & \\
\hline 97\% LDPE 3\% HK & 41.6 & 3.3 \\
\hline 94\% LDPE 6\% HK & 43.1 & 6.6 \\
\hline 91\% LDPE 9\% HK & 43.8 & 8.0 \\
\hline 88\% LDPE 12\% HK & 43.9 & 8.2 \\
\hline 85\% LDPE 15\% HK & 41.2 & 2.2 \\
\hline
\end{tabular}


Pada Jadual 3 menunjukkan peratusan peningkatan indeks kekerasan yang dibandingkan dengan sampel $100 \%$ LDPE. Pada keseluruhannya peratusan meningkat tetapi peratusan ini meningkat dari Sampel 97\% LDPE 3\% HK sehingga sampel 88\% LDPE 12\% HK, kemudian ia menurun pada sampel $85 \%$ LDPE 15\% HK, tetapi penurunan ini hanya sedikit, tidak kurang daripada nilai indeks 100\% LDPE. Keputusan ini menunjukkan LDPE sesuai digabungkan dengan HK, jika dilihat pada sudut kekerasan. Apabila indeks kekerasan meningkat maka semakin keras sesuatu bahan tetapi sifat liat bahan akan menurun.

Merujuk kepada graf yang telah diplotkan pula menunjukkan keputusan yang jelas kelihatan perbezaannya antara nisbah campuran yang berlainan. Gabungan LDPE dengan pengisi menunjukkan kekerasan sampel semakin bertambah pada sesetengah nisbah campuran polimer dengan bahan tambah dan menurun sedikit pada nisbah campuran $85 \%$ LDPE $15 \%$ HK. Nilai purata kekerasan pada setiap nisbah campuran pengisi dengan LDPE menunjukkan purata nilai kekerasan yang agak baik dan boleh dikatakan pada setiap nisbah campuran pengisi dengan LDPE meningkat jika dibandingkan dengan 100\% LDPE (tulen). Ini jelas menunjukkan plastik yang berketumpatan rendah, sesuai digabungkan dengan pengisi yang digunakan di dalam kajian. Peningkatan ini berlaku mungkin disebabkan oleh proses pembuatannya iaitu menggunakan mesin suntikan panas, dimana apabila suhu tinggi dikenakan HK akan terbakar dan akan membentuk karbon seterusnya memberi kesan kepada ujian kekerasan. Suhu lebur untuk LDPE boleh mencapai $290^{\circ} \mathrm{C}$ semasa menggunakan mesin suntikan panas sedangkan suhu penguraian $\mathrm{HK} 97.1^{\circ} \mathrm{C}$. Menurut Brooks (2000), apabila bahan pengisi dicampurkan kedalam polimer dalam lingkungan $10 \%$ sehingga $50 \%$ diketahui peningkatan kestabilan demensi komponen berkaitan dengan rintangan ubah bentuk plastik.

\subsection{Pemerhatian Keseluruhan}

Pemerhatian keseluruhan adalah dilakukan untuk memilih bahan yang paling baik jika dibandingkan dengan 100\% LDPE dan dengan peratus nisbah campuran yang lain. Jadual 4 menunjukkan perbandingan peratusan $0 \%$ HK dengan peratusan yang lain dan pemilihan sampel yang terbaik diantara nisbah campuran HK. Pemilihan dibuat berdasarkan sifat-sifat yang diperolehi dari pada analisis dan ujikaji yang dijalankan.

Untuk sampel ujian hentaman dan ujian kekerasan, sampel yang paling baik adalah sampel $12 \% \mathrm{HK}$ yang mana nilai indeks kekerasan meningkat paling tinggi manakala tenaga hentaman yang diperlukan untuk mematahkan sampel menurun paling sedikit pada sampel ini. Untuk sampel ujian tegangan pula adalah sampel 3\% HK yang paling baik kerana nilai sifat menurun paling sedikit berlaku pada sampel ini. 
Jadual 4: Menunjukkan perbandingan sifat diantara 0\% HK dengan peratus yang lain

\begin{tabular}{|c|c|c|c|c|c|c|}
\hline Ujikaji & Sifat & $3 \% \mathrm{HK}$ & $6 \% \mathrm{HK}$ & $9 \% \mathrm{HK}$ & $12 \% \mathrm{HK}$ & $15 \% \mathrm{HK}$ \\
\hline Kekerasan & Indeks Kekerasan & 3.3 & 6.6 & 8 & 8.2 & 2.3 \\
\hline
\end{tabular}

Indeks kekerasan yang terbaik

\subsection{Kesimpulan}

Setelah melakukan ujian kekerasan, skop dan objektif kajian dapat dipenuhi sepenuhnya. Melalui ujian yang dijalankan dan analisis data yang dibuat didapati perubahan sifat berlaku keatas bahan tulen apabila dicampurkan dengan peratusan nisbah HK. Perubahan yang berlaku, sama ada semakin tinggi atau menurun adalah disebabkan oleh kesan penambahan HK terhadap LDPE. Objektif utama di dalam projek ini adalah melihat kesan kekerasan apabila dibandingkan dengan 100\% LDPE.

Untuk ujian kekerasan sampel 12\% HK adalah sampel yang paling baik jika dibandingkan dengan sampel yang lain. Sampel ini menunjukkan peningkatan yang paling tinggi jika dibandingkan dengan 100 \% LDPE. Oleh kerana suhu penguraian LDPE hampir sama dengan suhu penguraian HK, keserasian bahan tambah dengan LDPE adalah baik dan mampu mengubah sifat asal LDPE. Semua sampel menunjukkan penigkatan nilai indeks kekerasan (rujuk Jadual 4). Bahan tambah yang disebatikan dengan LDPE mampu memperbaiki nilai indek kekerasan LDPE kerana keberkesanan bahan pengisi yang mampu bergantung kepada ikatan rantai polimer. Menurut Rao dan Lee (1994), dengan penambahan bahan pengisi yang berbentuk ion atau partikal dalam polimer akan menyebabkan nilai kekerasan komposit polimer dengan pengisi berkecenderungan untuk bertambah. 


\section{Rujukan}

G. R. Rao and E. H. Lee 3. (1995). "Wear properties of high energy ion-.Implanted PC." Journal of Materials Research."10. 190-201.

Nyamol George, S. S. Bhagawan, N. Prabhakaran and Sabu Thomas (1995). "Short Pineapple-LeafReinforced Low-Density Polyethylene Composites." Journal of Applied Polymer Science. Bil. 57 m.s. 843 $-854$

R.Brooks. (2000). "Injection Molding Based Techiques." Anthony Kelly, Carl .Zweben, Ramesh Talreja and Jan-Anders E.Manson. "Polymer Matrix Composite." Volume 2. United Kingdom. Elsevier. 1006-1008. 